\title{
The Management of GI bleeding after Gastric Bypass Surgery
}

\section{Riley K Kitamura*, Jane Lee and Lester Brian Katz}

\section{Department of Surgery, Mount Sinai Hospital, New York, USA}

${ }^{*}$ Corresponding author: Riley Kitamura, General Surgery Resident, Mount Sinai Hospital New York, E-mail: Riley.kitamura@mssm.edu

\section{Introduction}

Obesity rates in the United States continue to increase. Currently, $34.9 \%$ of adults are considered obese (BMI $\left.>30 \mathrm{mg}, / \mathrm{kg}^{2}\right)$ [1,2], $5.1 \%$ of these individuals qualify as morbidly obese (Body Mass Index $>40 \mathrm{mg} /$ $\mathrm{kg}^{2}$ ) and are at increased risk of obesity-related complications including early death [3].

Roux-en-Y gastric bypass (RNYGB) has consistently demonstrated good results in long-term weight loss and improvements in obesityrelated comorbidities, and is similarly increasing in frequency [4]. However, gastric remnant pathology presents a diagnostic challenge, and although rare, bleeding and ulceration from peptic ulcer disease has been reported and can be fatal [3,5-8].

We present a case of life-threatening hemorrhage from multiple gastric ulcerations in a patient after RNYGB, and a management algorithm.

\section{Case}

A 38 year-old female with a history of psoriatic arthritis on chronic NSAID use, and obesity underwent a RNYGB in 2010. In 2013, she presented to an outsidehospital with massive GI bleed, requiring multiple transfusions and ICU monitoring. Subsequently, she underwent both upper and lower endoscopy, angiography, capsule endoscopy, and exploratory laparotomy-however, the source of her bleed was ultimately never found and her symptoms resolved spontaneously.

In 2014, she presented to our ED with complaint of melanotic stool and diffuses abdominal pain of several weeks. She was initially tachy cardic, mildly hypotensive, and her initial hemoglobin levels was $7.4 \mathrm{~g} / \mathrm{dl}$. She was immediately resuscitated. Given her prior history and negative work-up, our team opted to perform a Technetium-99m $(99 \mathrm{mTc})$ red blood cell scan initially. This was inconclusive, however there was a "questionable faint focus of uptake confined to the left upper quadrant", which persisted on subsequent scans (Figure 1).

The patient was taken to the operating room the following day for laparoscopy, and an intra-operative endoscopy via gastrostomy of the gastric remnant. This revealed the gastric remnant to be distended and full of clotted blood. At this time, completion gastrectomy was performed and multiple ulcerations approximately $1 \mathrm{~cm}$ in size were noted along the greater curvature of the excised stomach (Figures $2,3)$. Pathology noted antral and fundic gland mucosa with ulceration, hemorrhage, and submucosal fibrin deposition. Infection with Helical pylori was negative. Post-operatively, the patient recovered well and has had resolution of her symptoms.

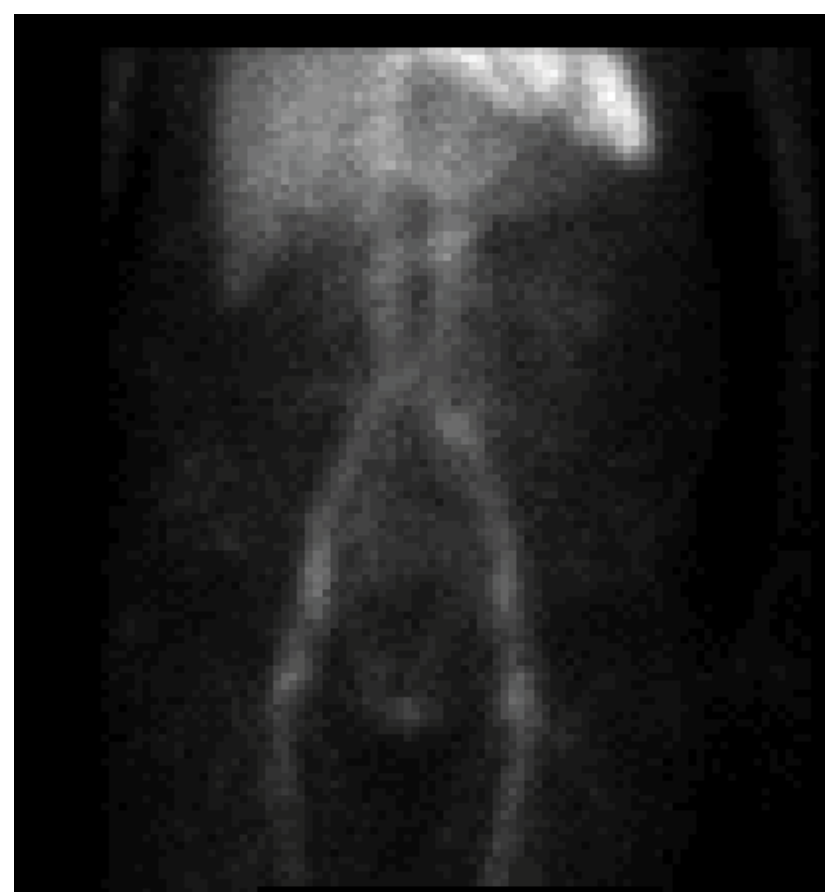

Figure 1: Technetium-99m (tagged RBC scan) with faint uptake in the left upper quadrant.

\section{Discussion}

In the management of morbid obesity, RNYGB reduces risk in developing obesity-related cardiovascular, infectious, endocrine, psychiatric and mental disorders [9]. The need for gastric bypass continues to increaseas the rate of obesity increases worldwide [10].

Ulceration in the gastric remnant is a rare complication that can occur months to years later and often present a diagnostic challenge. Historically, bleeding occurs from the staple lines with an incidence of 0.4 to $4.4 \%$ and occurs due to ulceration at the gastrojejunal staple line in the majority of cases, but may also occur from the duodenal stump or jejunojejunoal anastomosis [11].

Traditionally, occult bleed in gastric bypass was managed with intraoperative endoscopy via gastrostomy. However, Kuga et al. achieved successful visualization of the gastric remnant in $35 / 40$ (85\%) patients with double-balloon push endoscopy and speculate

\section{ClinMed International Library}

Citation: Kitamura RK, Lee J, Katz LB (2015) The Management of Gl bleeding after Gastric Bypass Surgery. Int J Surg Res Pract 2:026

Received: June 08, 2015: Accepted: August 13, 2015: Published: August 15, 2015

Copyright: @ 2015 Kitamura RK. This is an open-access article distributed under the terms of the Creative Commons Attribution License, which permits unrestricted use, distribution, and reproduction in any medium, provided the original author and source are credited. 


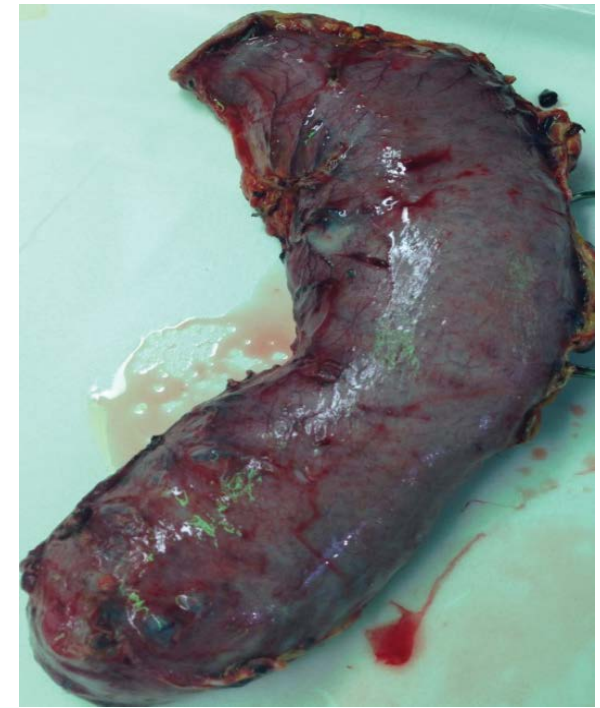

Figure 2: Excised gastric remnant distended with blood.

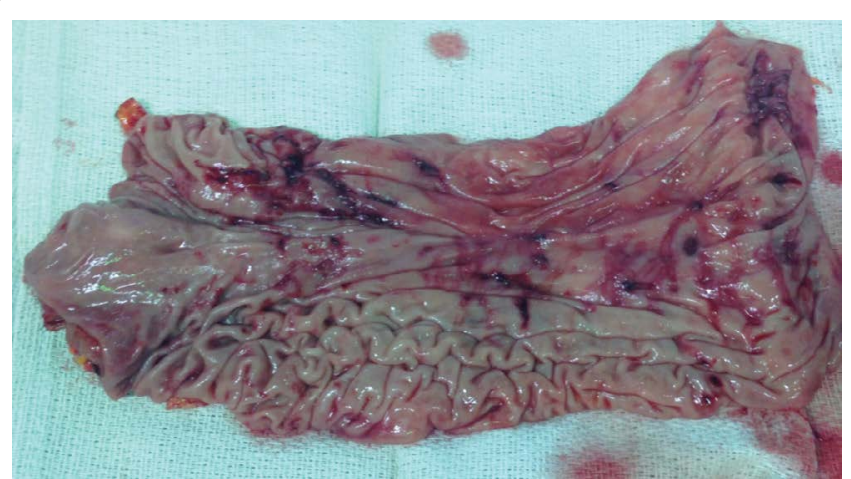

Figure 3: Gastric lumen with several gastric ulcerations along fundus (arrows).

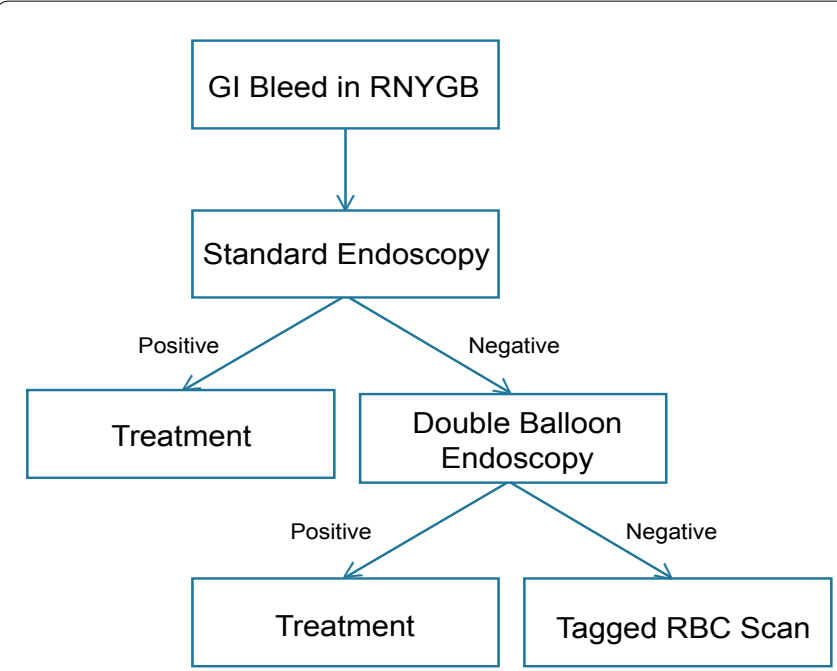

Figure 4: Proposed algorithm for the management of GI bleeds after RNYGB in the hemodynamically stable patient

that with newly developed endoscopes, therapeutic intervention may soon be possible [12]. Alternatively, Sundbom et al. described successful endoscopic evaluation via percutaneous gastrostomy [13]. Authors have described advanced imaging techniques (i.e. CT virtual gastroduodenoscopy) to detect gastric remnant lesions-however this may not be helpful in acute situation or in a hemodynamically unstable patient [14]. It will be interesting to see if these modalities will be useful as surveillance of the bypassed segment in the future.

In patients who present with massive hemorrhage or are hemodynamic unstable, the best option may still be operative intervention with open or laparoscopic gastrostomy and endoscopy [7]. Furthermore, patients who are found with duodenal ulcer would likely benefit from completion gastrectomy to reduce the risk of rebleeding.

Ultimately in our patient, operative intervention was performed after a tagged red blood cell scan suggested left upper quadrant pooling. In our review, this approach had been reported once in a case reportin 1987 by Spires et al. [15]. Technetium-99m scans are extremely sensitive, able to detect bleeding at the rate of $0.1 \mathrm{cc} / \mathrm{hr}$, and may be repeated revealing increased uptake over successive scans [16]. Thus, tagged red blood cell scans offer a unique solution in patients for which gastric remnant bleeding is suspected.

In the management of UGI bleed after RNYGB in the hemodynamically stable patient, we recommend direct evaluation with UGI endoscopy as the standard initial management. Advanced endoscopic maneuvers can be considered if the gastric remnant cannot be visualized, such as double balloon endoscopy. Following this, tagged red blood cell scan should be considered if the diagnosis is still lacking. Finally, if this continues to be negative, a laparoscopic endoscopy via gastrostomy of the gastric remnant is the final and most invasive test (Figure 4). Diagnostic laparoscopy and intraoperative endoscopy may also be considered in the hemodynamically unstable patient for whom the suspicion for gastric remnant hemorrhage is high.

Gastric and duodenal ulceration from the bypassed segment is most commonly due to marginal ulcer and reported to have a $7 \%$ incidence rate [17], but other sources of bleed include bile gastritis, helical pylori infection, and gastric cancer. In our review, this is the first report of multiple gastric fundus ulcerations causing hemorrhagic bleed after RNYGB. It is likely these ulcers formed secondary to NSAID use for psoriatic arthritis.

Sasse et al. similarly described a possible link between NSAID use and ulceration of the gastric remnant, and now advocate a "zero tolerance" policy for gastric bypass patients [18]. Additionally, avoidance of alcohol, tobacco, and continuation of empiric PPI therapy is advocated in several studies to prevent ulcer formation.

\section{Conclusion}

Increasing obesity rates in the US and worldwide will continue to provide the need for gastric bypass surgery. Gastric remnant bleeding presents a diagnostic challenge and may impact patient morbidity and mortality if not discovered expediently. Traditionally, gastric bleeding was managed with operative gastrostomy and endoscopy. This may still be the best option in the unstable patient. However, less invasive techniques, particularly double-balloon endoscopy are very promising, and if this is not available or the patient is not amenable to endoscopic intubation, a tagged red blood cell scan may be considered as intermediary steps in diagnostic management.

\section{References}

1. Ng M, Fleming T, Robinson M, Thomson B, Graetz N, et al. (2014) Global, regional, and national prevalence of overweight and obesity in children and adults during 1980-2013: a systematic analysis for the Global Burden of Disease Study 2013. Lancet 384: 766-781.

2. Ogden CL, Carroll MD, Kit BK, Flegal KM (2014) Prevalence of childhood and adult obesity in the United States, 2011-2012. JAMA 311: 806-814.

3. Zerey M, Sigmon LB, Kuwada TS, Heniford BT, Sing RF (2008) Bleeding duodenal ulcer after roux-en-Y gastric bypass surgery. J Am Osteopath Assoc 108: 25-27.

4. Tice JA, Karliner L, Walsh J, Petersen AJ, Feldman MD (2008) Gastric banding or bypass? A systematic review comparing the two most popular bariatric procedures. Am J Med 121: 885-893.

5. Coblijn UK, Lagarde SM, Tuynman JB, van Meyel JJ, van Wagensveld BA (2013) Delayed massive bleeding two years after Roux-en-Y gastric bypass. JSLS 17: 476-480.

6. Mittermair R, Renz O (2007) An unusual complication of gastric bypass: perforated duodenal ulcer. Obes Surg 17: 701-703. 
7. Ivanecz A, Sremec M, Ceranic D, Potrc S, Skok P (2014) Life threatening bleeding from duodenal ulcer after Roux-en- $Y$ gastric bypass: Case report and review of the literature. World J Gastrointest Endosc 6: 625-629.

8. Puri V, Alagappan A, Rubin M, Merola S (2012) Management of bleeding from gastric remnant after Roux-en-Y gastric bypass. Surg Obes Relat Dis 8: e3-5.

9. Christou NV, Sampalis JS, Liberman M, Look D, Auger S, et al. (2004) Surgery decreases long-term mortality, morbidity, and health care use in morbidly obese patients. Ann Surg 240: 416-423.

10. Nguyen NT, Root J, Zainabadi K, Sabio A, Chalifoux S, et al. (2005) Accelerated growth of bariatric surgery with the introduction of minimally invasive surgery. Arch Surg 140: 1198-1202.

11. Heneghan HM, Meron-Eldar S, Yenumula $P$, Rogula T, Brethauer SA, et al (2012) Incidence and management of bleeding complications after gastric bypass surgery in the morbidly obese. Surg Obes Relat Dis 8: 729-735.

12. Kuga R, Safatle-Ribeiro AV, Faintuch J, Ishida RK, Furuya CK Jr, et al. (2007) Endoscopic findings in the excluded stomach after Roux-en- $Y$ gastric bypass surgery. Arch Surg 142: 942-946.
13. Sundbom M, Nyman R, Hedenström H, Gustavsson S (2001) Investigation of the excluded stomach after Roux-en-Y gastric bypass. Obes Surg 11: 25-27.

14. Silecchia G, Catalano C, Gentileschi P, Elmore U, Restuccia A, et al. (2002) Virtual gastroduodenoscopy: a new look at the bypassed stomach and duodenum after laparoscopic Roux-en-Y gastric bypass for morbid obesity. Obes Surg 12: 39-48.

15. Spires WV, Morris DM (1987) Bleeding duodenal ulcer after gastric bypass procedure for obesity. South Med J 80: 1325-1326.

16. Cave DR (2005) Obscure gastrointestinal bleeding: the role of the tagged red blood cell scan, enteroscopy, and capsule endoscopy. Clin Gastroenterol Hepatol 3: 959-963.

17. Rasmussen JJ, Fuller W, Ali MR (2007) Marginal ulceration after laparoscopic gastric bypass: an analysis of predisposing factors in 260 patients. Surg Endosc 21: 1090-1094

18. Sasse KC, Ganser J, Kozar M, Watson RW, McGinley L, et al. (2008) Seven cases of gastric perforation in Roux-en-Y gastric bypass patients: what lessons can we learn? Obes Surg 18: 530-534. 